\title{
Dealcoholised beers reduce atherosclerosis and expression of adhesion molecules in apoE-deficient mice
}

\author{
Nuria Martinez ${ }^{1}$, Mireia Urpi-Sarda ${ }^{2}$, Miguel Angel Martinez-Gonzalez ${ }^{3}$, Cristina Andres-Lacueva ${ }^{2}$ and \\ Maria Teresa Mitjavila ${ }^{1 *}$ \\ ${ }^{1}$ Department of Physiology, Faculty of Biology, INSA, University of Barcelona, Avinguda Diagonal 645, O8028 Barcelona, \\ Spain \\ ${ }^{2}$ Department of Nutrition and Food Science, XaRTA, INSA, INGENIO-CONSOLIDER Program, Fun-C-Food CSD2007-063, \\ Faculty of Pharmacy, University of Barcelona, Avinguda Joan XXIII s/ $n$, O8028 Barcelona, Spain \\ ${ }^{3}$ Department of Preventive Medicine and Public Health, Medical School, University of Navarra, Irunlarrea 1, 31080 \\ Pamplona, Spain
}

(Received 25 March 2010 - Revised 17 September 2010 - Accepted 20 September 2010 - First published online 7 December 2010)

\section{Abstract}

Polyphenols exert beneficial effects in atherosclerosis. The crucial step in atherosclerosis is the recruitment of monocytes to the subendothelial space, induced by endothelial adhesion molecules through the activation of factors such as NF- $\kappa$ B. We studied the effect of a dealcoholised lager beer (DLB) and a dealcoholised dark beer (DDB) on atherosclerotic lesions, and the underlying mechanisms. Dealcoholised beers were administered in the diet $(42 \mathrm{ml} / \mathrm{kg}$ body weight per $\mathrm{d})$ to 4 -week-old male apoE knockout (apoE - / - ) mice for 20 weeks. The atherosclerotic lesions in the thoracic aorta were reduced by $44 \%(P=0.003)$ and $51 \%(P<0 \cdot 001)$ in DLB- and DDB-treated mice, respectively. Also, the mRNA expressions of the endothelial adhesion molecules in the total aorta were decreased: P-selectin showed a $17 \%(P=0.004)$ reduction in DDB-treated mice; vascular cell adhesion molecule-1 (VCAM-1) was decreased by $20 \%$ $(P=0.012)$ and $32 \%(P=0.001)$ in DLB- and DDB-treated mice, respectively; intercellular adhesion molecule-1 (ICAM-1) showed a 14\% $(P=0.014)$ reduction in DLB-treated mice. The protein expressions of these molecules and NF- $\mathrm{kB}$ were studied in the aortic root. P-selectin was decreased by $37 \%(P=0 \cdot 012)$ in DDB-treated mice; VCAM-1 was reduced by $48 \%(P=0 \cdot 001)$ and $54 \%(P<0 \cdot 001)$ in DLB- and DDBtreated mice, respectively; ICAM-1 was decreased by $25 \%(P=0.028)$ and $30 \%(P=0.018)$ in DLB- and DDB-treated mice, respectively; NF$\mathrm{\kappa B}$ was reduced by $46 \%(P=0.042)$ in DDB-treated mice. In conclusion, dealcoholised beers protected apoE $-/-$ mice against atherosclerosis, through the modulation of endothelial adhesion molecules, possibly induced by NF-кB.

Key words: Atherosclerosis: Beer polyphenols: Adhesion molecules: NF-кB

Atherosclerosis is a multi-factorial disease characterised by lipid deposition, cellular infiltration, proliferation of the smooth muscle cells and intimal thickening with subsequent thrombus formation ${ }^{(1)}$. ApoE deficiency causes defects in lipolysis, and it has an important role in the transport of TAG and cholesterol by VLDL and chylomicrons $^{(2)}$. Thus, apoE knockout (apoE -/-) mice have high lipid levels in their plasma and cholesterol-rich $\beta$-VLDL and spontaneously develop atherosclerosis ${ }^{(2)}$, being an accepted model for the study of the modulation of atherosclerotic lesions by dietary factors ${ }^{(3)}$.

The transendothelial migration of monocytes is an important early step in atherosclerosis and is mediated by endothelial adhesion molecules. Selectins are involved in the primary monocyte-endothelium interaction (tethering and rolling) ${ }^{(4)}$. Vascular cell adhesion molecule-1 (VCAM-1) and intercellular adhesion molecule-1 (ICAM-1) are responsible for the secondary monocyte-endothelium interaction (firm adhesion) ${ }^{(5)}$, and their expression is up-regulated in atherosclerotic lesions of hypercholesterolaemic mice ${ }^{(6)}$. NF-кB is a redox-sensitive inducible transcription factor that is activated in response to various extracellular stimuli and regulates the mRNA expression of endothelial adhesion molecules ${ }^{(7)}$.

An inverse association between flavonoids ${ }^{(8)}$, red wine ${ }^{(9)}$ and beer ${ }^{(10)}$ intake and CHD development has been

Abbreviations: apoE $-/-$, apoE knockout; DB, dark beer; DDB, dealcoholised DB; DLB, dealcoholised lager beer; ICAM-1, intercellular adhesion molecule-1; LB, lager beer; VCAM-1, vascular cell adhesion molecule-1.

*Corresponding author: Professor M. T. Mitjavila, fax +3493 4110358, email mmitjavila@ub.edu 
demonstrated. Polyphenols have antioxidant activity in vitro $^{(11)}$ and ex vivo ${ }^{(12,13)}$, which is related to cardiovascular protection ${ }^{(8)}$. There is a long list of beverages and foods with a high phenolic content, and beer provides more antioxidants per day than wine ${ }^{(14)}$ as it is consumed in larger amounts than wine in the $\mathrm{USA}^{(15)}$ and Europe ${ }^{(16)}$. It is a popular beverage that has been produced for over 4000 years, and a moderate consumption of beer is now related to a decreased plasma C-reactive protein concentration, a biomarker for vascular inflammation in early stages of atherosclerosis, mediated by the alcohol present in beer ${ }^{(17)}$. However, the presence of polyphenols in beers raises the question of whether health benefits may be associated with the non-alcoholic components of beers.

We hypothesise that the phenolic content reduces the progression of atherosclerosis by modulating one important initial step in the disease, the transmigration of monocytes to the intima. Thus, we studied the beneficial effect of polyphenols from beers on the development of atheroma plaques by supplementing the diet of apoE $-/-$ mice with two different types (lager (LB) and dark (DB)) of dealcoholised beers. As the internalisation of monocytes through the endothelium is regulated by endothelial adhesion molecules, we analysed their expression in the aorta of apoE $-/-$ mice and NF- $\mathrm{BB}$ involvement.

\section{Materials and methods \\ Chemicals}

Mineral and vitamin mixes of diets were purchased from ICN Biomedicals (Aurora, OH, USA). 4-Hydroxyhippuric acid $(>99 \%)$ was obtained from PhytoLab GmbH \& Co. KG (Vestenbergsgreuth, Germany). Vanillic acid, $m$ coumaric acid, tyrosol, hydroxytyrosol, 4-O-methylgallic acid and taxifolin $(>90 \%)$ were purchased from Extrasynthèse (Genay, France). HPLC-grade methanol, acetonitrile and formic acid were from Scharlau (Barcelona, Spain). The NucleoSpin kit for RNA extraction was purchased from Macherey-Nagel (Düren, Germany), and the kit for the retrotranscription was from Roche Diagnostics (Mannheim, Germany). The oligonucleotides for the PCR were obtained from Bonsai Technologies Group (Madrid, Spain). The optical cutting temperature was from Tissue-Tek (Dublin, Ireland). Rabbit anti-mouse Pselectin antibody was obtained from Chemicon Immunostains (Hampshire, UK), rat anti-mouse VCAM-1 was from eBioscience (San Diego, CA, USA), goat anti-mouse ICAM-1 was from R\&D Systems (Abingdon, UK) and rabbit anti-mouse NF-кB-p65 (Ser 276) was obtained from Thermo Fisher Scientific (Chesire, CT, USA). The secondary antibodies for immunofluorescence (donkey anti-rabbit 647, donkey anti-rat 488 and donkey anti-goat 546) were purchased from Molecular Probes (Poort Gebouw, The Netherlands). All other standards for analyses of beers and plasma, components of diets and reagents used were obtained from Sigma-Aldrich-Fluka (St Louis, MO, USA).

\section{Animals and diets}

Male C57BL/6J apoE - /- mice (Charles River, L'Arbresle, France) were housed in temperature $\left(21-23^{\circ} \mathrm{C}\right)$ and humidity (40-60\%)-controlled rooms and exposed to $12 \mathrm{~h}$ light $-12 \mathrm{~h}$ dark cycles. At 4 weeks of age, they were placed randomly into three groups of fourteen mice each and were fed one of the following semi-purified diets for 20 weeks: (1) a control diet; (2) a dealcoholised lager beer (DLB)-rich diet; (3) a dealcoholised dark beer (DDB)-rich diet (Table 1). The semi-purified diet was prepared weekly. Solid components of the diet were mixed with $210 \mathrm{ml} / \mathrm{kg}$ water (control diet) or with $210 \mathrm{ml} / \mathrm{kg}$ beer, which replaced the water in treated mice. The diet mixes were air dried for $18 \mathrm{~h}$ and stored at $-20^{\circ} \mathrm{C}$ to prevent oxidation and loss of antioxidants. The dose of dealcoholised beers that mice ingested with the diet is $42 \mathrm{ml}$ beer/ $\mathrm{kg}$ body weight/d which is equivalent to about $500 \mathrm{ml}$ of daily consumption for humans, as mice have more surface area per unit of weight than humans ${ }^{(18)}$. All diets were supplemented with $0 \cdot 15 \%$ cholesterol to accelerate the development of atherosclerosis. The quantity was restricted to $5-6 \mathrm{~g} / \mathrm{d}$ to avoid differences in the diet and cholesterol ingestion. Food was provided and removed daily. All the mice were weighed weekly and examined after fasting overnight. Eight mice were used to evaluate the plasma lipid profile and the atherosclerotic lesions, and the other six were used to measure the phenols in the plasma; the adhesion molecules were measured by RT-PCR and immunofluorescence assays. The procedures and care of the animals were performed according to the University of Barcelona Ethical Committee for Animal Experimentation, following European Union guidelines.

Spanish commercial LB and DB were dealcoholised in a rotary evaporator at $30^{\circ} \mathrm{C}$ by progressively applying a vacuum up to $-70 \mathrm{mbars}$. The volume of ethanol was replaced by acidulated distilled water as reported previously $^{(19)}$. A mass spectrometer (Fisons MD800; Thermo Finnigan, Ringoes, NJ, USA) connected to a headspace gas

Table 1. Composition of semi-purified diets

\begin{tabular}{lccc}
\hline Components (g/kg diet) & Control & DLB & DDB \\
\hline Casein & 225 & 225 & 225 \\
Maize starch & 446 & 446 & 446 \\
Sucrose & 223 & 223 & 223 \\
Cellulose & 31 & 31 & 31 \\
DL-Met & 1 & 1 & 1 \\
Mineral mix & 14 & 14 & 14 \\
Vitamin mix & 10 & 10 & 10 \\
Maize oil & 48.5 & 48.5 & 48.5 \\
Cholesterol & 1.5 & 1.5 & 1.5 \\
Water or dealcoholised beers & 210 & 210 & 210 \\
\hline
\end{tabular}

DLB, dealcoholised lager beer; DDB, dealcoholised dark beer.

* The $210 \mathrm{ml}$ DLB or DDB replaced the $210 \mathrm{ml}$ water to compact the diet. 
chromatograph (GC8000-Top, Carlo Erba, Milan, Italy) was used to evaluate the residual ethanol in dealcoholised beers, with 2-methyl-1-propanol as the standard.

\section{Beer analysis}

Total phenols in 1:10 diluted beers were measured by the Folin-Ciocalteau colorimetric method ${ }^{(20)}$, with gallic acid as the standard, and the results are expressed as mm-gallic acid equivalents. The reducing power in 1:20 diluted beers was evaluated using the method described by Oyaizu ${ }^{(21)}$. Briefly, beers were mixed with PBS (200 mmol/1, pH 6.6) and $1 \%$ potassium ferricyanide and incubated for $20 \mathrm{~min}$ at $50^{\circ} \mathrm{C}$, and $10 \%$ TCA was then added. After centrifugation, $0 \cdot 1 \%$ ferric chloride was added and the absorbance was measured at $690 \mathrm{~nm}$. Quercetin was used as the standard, and values are expressed as mm-quercetin equivalents.

The determination and quantification of individual phenolic compounds ${ }^{(22)}$ in dealcoholised beers (DLB and DDB) were analysed directly by LC tandem MS (LC-MS/MS) ${ }^{(23)}$ adapted to the matrix of beer. The concentrations of phenolic compounds in beers are expressed as $\mathrm{mg} / \mathrm{l}$.

\section{LC tandem MS}

LC analyses were performed using an Agilent 1200 system equipped with a quaternary pump and a refrigerated autosampler plate (Waldbronn, Germany). An Applied Biosystems API 3000 Triple Quadrupole mass spectrometer (PE Sciex, Concord, ON, Canada), equipped with a Turboionspray ionisation source in negative mode, was used. A Phenomenex Luna $\mathrm{C}_{18}$ analytical column $(50 \times 2.0 \mathrm{~mm}$ internal diameter, $5 \mu \mathrm{m}$; Luna, Torrance, CA, USA) with mobile phase A ( $0 \cdot 1 \%$ formic acid in water) and B ( $0.1 \%$ formic acid in acetonitrile) was used. The linear gradient at a flow rate of $400 \mu \mathrm{l} / \mathrm{min}$ was (\% mobile phase $\mathrm{B}$, time $(\min ))(8,0),(50,4),(100,5 \cdot 2)$ and $(100,7)^{(23)}$. In each case, the column was re-equilibrated for $6 \mathrm{~min}$, and the sample volume injected was $10 \mu \mathrm{l}$. MS/MS parameters used were as follows: capillary voltage, $-3700 \mathrm{~V}$; focusing potential, $-200 \mathrm{~V}$; entrance potential, $-10 \mathrm{~V}$; declustering potential, $-50 \mathrm{~V}$; nebuliser gas, 10 (arbitrary units); curtain gas, 12 (arbitrary units); collision gas, 5 (arbitrary units); auxiliary gas temperature, $400^{\circ} \mathrm{C}$; auxiliary gas flow rate, $6000 \mathrm{~cm}^{3} / \mathrm{min}$. The collision energy for phenolic acids was optimised for each compound as described elsewhere ${ }^{(23)}$. For quantification purposes, data were collected in the multiple reaction monitoring mode, in which the transition of parent and product ions specific for each compound is tracked.

\section{Plasma analyses}

At the end of the treatment period (20 weeks) and after a 14-16 h fasting, mice were anaesthetised with $150 \mathrm{mg} / \mathrm{kg}$ ketamine $-10 \mathrm{mg} / \mathrm{kg}$ xilacin and exsanguinated by left ventricle puncture. Plasma was obtained by blood centrifugation at $1770 \mathrm{~g}$ for $15 \mathrm{~min}$ at $4^{\circ} \mathrm{C}$ and was stored at $-80^{\circ} \mathrm{C}$ until analysis.

Plasma concentrations of TAG and total cholesterol were evaluated enzymatically using commercial kits (Randox, Crumlin, UK).

\section{Bioavailability of beer phenols in the plasma}

The bioavailability of beer phenols was assessed by the analysis of phenolic microbial metabolites because the plasma samples were from fasted mice ${ }^{(24-26)}$. They were evaluated following a published and validated methodology as described previously ${ }^{(23)}$. Briefly, $400 \mu$ l plasma were spiked with ethyl gallate as an internal standard and subjected to enzymatic hydrolysis. Solid-phase extraction was performed using Oasis MCX ninety-six-well plates (Waters, Milford, MA, USA). The plates were conditioned with methanol and $2 \%$ formic acid in water. The hydrolysed samples were then loaded onto a plate and washed in this acidified water. The analytes were then eluted with methanol and evaporated to dryness. Residues were reconstituted with taxifolin dissolved in mobile phase A ( $0 \cdot 1 \%$ formic acid in water) and analysed by LC-MS/MS.

To evaluate plasma samples from mice fed for 20 weeks with dealcoholised beers, we prepared calibration curves in the blank plasma in the range of concentrations expected, by supplementation with known concentrations of phenolic acids and flavonoids.

\section{Atherosclerotic lesions}

The thoracic aorta (including the ascending aorta, the aortic arch and the descending aorta) was isolated after perfusion with $4 \%$ paraformaldehyde, cleaned of attached connective tissue, opened lengthwise and fixed in $4 \%$ paraformaldehyde overnight. The atherosclerotic lesions were visible and clearly distinguishable from the lesion-free areas on the luminal surface of the vessels without staining. Images were taken on a digital camera (Olympus BX-40, Hamburg, Germany) and recorded in 24-bit true image format, and the lesions were quantified with the AnalysisSoft Imaging System software (Olympus Soft Imaging Solutions $\mathrm{GmbH}$, Münster, Germany). The lesion area from each mouse is expressed as the percentage of the total luminal surface.

\section{P-selectin, vascular cell adhesion molecule-1 and intercellular adhesion molecule-1 mRNA expression by $R T-P C R$}

RNA extraction from the total aorta (thoracic and abdominal aorta) was carried out using the NucleoSpin Macherey-Nagel kit. The quality of the extraction was checked in a $0.8 \%$ agarose gel, and it was quantified by 
spectrophotometry (Genesis UV, Thermo Spectronic, Waltham, MA, USA).

RT was performed with $1 \mu \mathrm{g}$ total RNA using the Roche Diagnostics kit, and the PCR was done with a Thermocycler Tpersonal $48230 \mathrm{~V}$ (Biometra, Goettingen, Germany). We designed the oligonucleotide sequences for P-selectin, VCAM-1 and ICAM-1 (Table 2). The hypoxanthineguanine phosphoribosyl transferase gene was used as an internal standard in the reaction for normalisation using specific primer sequences. Primers were tested for linearity over cycle number, and the analyses were performed in the linear portion of the curve, allowing semi-quantitative analysis of mRNA amount. The annealing temperature was set at $53^{\circ} \mathrm{C}$ for all gene sequences. PCR products were run on a $2 \%$ agarose gel, and ethidium bromide bands were visualised and quantified with ImageJ $1.40 \mathrm{~g}$ (National Institutes of Health, Bethesda, MD, USA). Each amplified product was normalised by dividing the average grey level of the signal by that of the corresponding hypoxanthine-guanine phosphoribosyl transferase PCR band. Data are expressed as the percentage of mRNA expression with respect to the control group.

P-selectin, vascular cell adhesion molecule-1, intercellular adhesion molecule-1 and NF- $\kappa B$ expression by immunofluorescence

The heart was perfused, fixed with $4 \%$ paraformaldehyde and extracted from the mice. Each heart was cryoprotected overnight with $35 \%$ sucrose at $4^{\circ} \mathrm{C}$ under mild shaking and was then frozen on a cryostat mount with optical cutting temperature. Serial cross-sections of $10 \mu \mathrm{m}$ thickness of the aortic root were obtained from the top of the left ventricle, where the aortic valves were first visible, up to where the valve cusps disappeared.

Five cross-sections (one for a negative control) of the aortic root of each mouse were washed in $10 \mathrm{~mm}$-PBS and $20 \mathrm{~mm}-$ glycine and blocked with $1 \%$ bovine serum albumin in $10 \mathrm{~mm}$-PBS. We used the following primary antibodies: rabbit anti-mouse P-selectin $(5 \mathrm{mg} / 1)$; rat antimouse VCAM-1 (20 mg/l); goat anti-mouse ICAM-1 (2 mg/ 1); rabbit anti-mouse NF-кB-p65 (Ser 276) (20 mg/1). After incubation with the corresponding secondary antibodies (donkey anti-rabbit 647, donkey anti-rat 488 and donkey anti-goat 546) in a concentration of $4 \mathrm{mg} / \mathrm{l}$, the images were captured with a confocal inverted fluorescence microscope (Olympus Fluoview 500, IX-70), and the fluorescence was quantified in lesion areas by Metamorph analyser software (Universal Imaging Corporation, San Diego, CA, USA). Data are expressed as the percentage of NF-кB expression with respect to the control group.

\section{Statistical analysis}

Values are means with their standard errors. In the phenolic composition of dealcoholised beers, values are means and standard deviations. The LB:DLB and the DB:DDB were compared by Hotelling's $T^{2}$ statistic analysis, and the samples were independently drawn from two independent multivariate normal distributions of two dimensions. Comparisons between alcoholised and dealcoholised beers were carried out by Student's $t$ test for paired samples. The differences between groups of mice treated with control diets and diets supplemented with dealcoholised beers were analysed by one-way ANOVA and least significant difference multiple comparison test for post hoc analysis. Differences were considered significant at $P<0 \cdot 05$. All statistical analyses were performed using SPSS 12.0 software (SPSS, Inc., Chicago, IL, USA).

\section{Results}

\section{Beer analyses}

The peaks of residual ethanol and the standard (2-methyl1-propanol) in beers after rotary evaporation were detected at 5.58 and $7.64 \mathrm{~min}$, respectively, and the beers were considered non-alcoholic.

Dealcoholisation did not alter the total phenol content in either type of beer (5.68 (SE 0.29) and 6.15 (SE 0.54) mmgallic acid equivalents for LB and DLB, respectively, and 5.96 (sE 0.31) and 6.38 (sE 0.91) mm-gallic acid equivalents for DB and DDB, respectively). No significant differences were observed in beers in terms of the reducing power before and after dealcoholisation (1.58 (SE 0.04) and 1.54 (SE 0.02) mm-quercetin equivalents for LB and DLB, respectively, and 1.69 (SE 0.04) and 1.74 (SE 0.06) mMquercetin equivalents for $\mathrm{DB}$ and $\mathrm{DDB}$, respectively), but DB had a significant greater reducing power than LB.

Individual phenolic composition of dealcoholised beers is shown in Table 3 .

\section{Body weight and plasma analyses}

All mice thrived and gained similar amounts of weight throughout the study (Table 4).

Table 2. Sequences of primers for semi-quantitative RT-PCR

\begin{tabular}{lclc}
\hline Gene & Accession number & \multicolumn{1}{c}{ Sense primer } & \multicolumn{1}{c}{ Antisense primer } \\
\hline$P$-selectin & NM 011347 & GCTCACGGAGAGTTTGGTGT & AAGTGGTGTTCGGACCAAAG \\
VCAM-1 & NM 011693 & ATTTTCTGGGGCAGGAAGTT & ACGTCAGAACAACCGAATCC \\
ICAM -1 & NM 010493 & TCACACTGAATGCCAGCTC & GTCTGCTGAGACCCCTCTTG \\
$h p r t$ & NM 013556 & GTTAAGCAGTACAGCCCCAAA & AGGGCATATCCAACAACAAACTT
\end{tabular}

VCAM-1, vascular cell adhesion molecule-1; ICAM-1, intercellular adhesion molecule-1; hprt, hypoxanthine-guanine phosphoribosyl transferase. 
Table 3. Phenolic composition of dealcoholised lager beer (DLB) and dealcoholised dark beer (DDB)*

(Mean values and standard deviations)

\begin{tabular}{|c|c|c|c|c|c|}
\hline \multirow[b]{2}{*}{ Polyphenol or metabolite } & \multirow[b]{2}{*}{ MRM } & \multicolumn{2}{|c|}{ DLB } & \multicolumn{2}{|c|}{ DDB } \\
\hline & & Mean & SD & Mean & SD \\
\hline \multicolumn{6}{|l|}{ Flavanols } \\
\hline Catechin & $289 / 245$ & $0 \cdot 190$ & 0.017 & 0.181 & 0.029 \\
\hline Epicatechin & $289 / 245$ & 0.075 & 0.003 & 0.068 & 0.010 \\
\hline Procyanidin B2 & $577 / 289$ & ND & & ND & \\
\hline \multicolumn{6}{|l|}{ Flavonols } \\
\hline Quercetin & $301 / 151$ & $0 \cdot 112$ & 0.014 & 0.087 & 0.009 \\
\hline \multicolumn{6}{|l|}{ Hydroxyphenylpropionic acids } \\
\hline 3,4-Dihydroxyphenylpropionic acid & $181 / 137$ & ND & & ND & \\
\hline 3-Hydroxyphenylpropionic acid & $165 / 121$ & ND & & ND & \\
\hline 4-Hydroxyphenylpropionic acid & $165 / 93$ & ND & & ND & \\
\hline Hydroferulic acid & $195 / 136$ & 0.197 & 0.024 & 0.128 & 0.021 \\
\hline \multicolumn{6}{|l|}{ Hydroxyphenylacetic acids } \\
\hline 3,4-Dihydroxyphenylacetic acid & $167 / 123$ & ND & & ND & \\
\hline 3-Methoxy-4-hydroxyphenylacetic acid & $181 / 137$ & ND & & ND & \\
\hline 3-Hydroxyphenylacetic acid & $151 / 107$ & ND & & ND & \\
\hline Phenylacetic acid & $135 / 91$ & ND & & ND & \\
\hline \multicolumn{6}{|l|}{ Hydroxycinnamic acids } \\
\hline$p$-Coumaric acid & $163 / 119$ & 0.186 & 0.028 & 0.167 & 0.020 \\
\hline$m$-Coumaric acid & $163 / 119$ & ND & & ND & \\
\hline o-Coumaric acid & $163 / 119$ & ND & & ND & \\
\hline Caffeic acid & $179 / 135$ & 0.030 & 0.004 & 0.022 & 0.003 \\
\hline Ferulic acid & $193 / 134$ & $0 \cdot 201$ & 0.025 & $0 \cdot 161$ & 0.010 \\
\hline Sinapic acid & $223 / 164$ & 0.099 & 0.010 & 0.092 & 0.013 \\
\hline Chlorogenic acid & $353 / 191$ & 0.009 & 0.001 & 0.009 & 0.0003 \\
\hline \multicolumn{6}{|l|}{ Hydroxybenzoic acids } \\
\hline Protocatechuic acid & $153 / 109$ & 0.011 & 0.002 & 0.007 & 0.001 \\
\hline 2,5-Dihydroxybenzoic acid & $153 / 109$ & ND & & ND & \\
\hline 2,6-Dihydroxybenzoic acid & $153 / 109$ & 0.120 & 0.066 & 0.097 & 0.032 \\
\hline 3,5-Dihydroxybenzoic acid & $153 / 109$ & ND & & ND & \\
\hline 3-Hydroxybenzoic acid & $137 / 93$ & 0.117 & 0.007 & 0.134 & 0.003 \\
\hline 4-Hydroxybenzoic acid & $137 / 93$ & ND & & ND & \\
\hline 2-Hydroxybenzoic acid & $137 / 93$ & 0.038 & 0.006 & 0.031 & 0.005 \\
\hline Vanillic acid & $167 / 152$ & ND & & ND & \\
\hline Gallic acid & $169 / 125$ & 0.005 & 0.001 & 0.004 & 0.001 \\
\hline 4-O-methylgallic acid & $167 / 108$ & ND & & ND & \\
\hline Syringic acid & $197 / 153$ & ND & & ND & \\
\hline \multicolumn{6}{|l|}{ Hydroxyhippuric acids } \\
\hline 4-Hydroxyhippuric acid & $194 / 100$ & ND & & ND & \\
\hline \multicolumn{6}{|l|}{ Tyrosols } \\
\hline Tyrosol & $137 / 93$ & ND & & ND & \\
\hline Hydroxytyrosol & $153 / 123$ & ND & & ND & \\
\hline \multicolumn{6}{|l|}{ Enterolignans } \\
\hline Enterodiol & $301 / 257$ & ND & & ND & \\
\hline Enterolactone & 297/253 & ND & & ND & \\
\hline \multicolumn{6}{|l|}{ Hydroxyphenylvalerolactones } \\
\hline Dihydroxyphenyl valerolactone & 207/163 & ND & & ND & \\
\hline
\end{tabular}

MRM, multiple reaction monitoring; ND, not detected.

* Data were collected in the MRM mode.

The concentrations of TAG and total cholesterol in the plasma after 20 weeks of treatment with dealcoholised beers were similar in the three groups (Table 4).

Plasma samples from mice treated with dealcoholised beers for 20 weeks were analysed by LC-MS/MS after sample hydrolysis and solid-phase extraction. Among the thirty-seven compounds studied, including phenols from beers and phenolic microbial metabolites, 4-hydroxyhippuric acid increased by $80 \%(P=0.005)$ and $68 \%$ $(P=0.01)$ after the DLB and DDB diets, respectively, and 3,4-dihydroxyphenylacetic acid increased by $84 \%$ $(P=0.019)$ and $82 \%(P=0.021)$ after the DLB and DDB diets, respectively. There were no other significant differences in the metabolites evaluated.

Dealcoholised beer-rich diets decreased the atherosclerotic lesions in the thoracic aorta of apoE - /- mice

Aortic lesions progressed to mature and complex fatty plaques resembling advanced human lesions. The mean percentage of the surface covered by the atherosclerotic lesions was $21 \%$ in the control group. However, the lesions were less extensive in the DLB $(12 \%, P=0.003)$ and DDB (11\%,P<0.001)-supplemented apoE $-/-$ mice (Fig. 1). 
Table 4. Effect of dietary supplementation with dealcoholised lager beer (DLB) and dealcoholised dark beer (DDB) for 20 weeks on bodyweight gain and plasma TAG and total cholesterol concentrations in apoE $-1-$ mice $^{*}$

(Mean values with their standard errors, $n 8$ )

\begin{tabular}{|c|c|c|c|c|c|c|}
\hline & \multicolumn{2}{|c|}{ Weight gain (g) } & \multicolumn{2}{|c|}{$\begin{array}{l}\text { Plasma TAG } \\
(\mathrm{mmol} / \mathrm{l})\end{array}$} & \multicolumn{2}{|c|}{$\begin{array}{l}\text { Plasma total } \\
\text { cholesterol } \\
\text { (mmol/l) }\end{array}$} \\
\hline & Mean & SE & Mean & SE & Mean & SE \\
\hline Control & $12 \cdot 85$ & 0.79 & 1.40 & 0.24 & 9.89 & 0.85 \\
\hline DLB & $15 \cdot 72$ & 0.57 & $1 \cdot 19$ & 0.17 & 11.97 & $1 \cdot 12$ \\
\hline DDB & $12 \cdot 03$ & 0.48 & $1 \cdot 11$ & 0.19 & 8.47 & 0.72 \\
\hline
\end{tabular}

* There were no differences between groups (one-way ANOVA).

\section{Dealcoholised beer-rich diets decreased the mRNA} expression of the endothelial adhesion molecules in the aorta of apoE - /- mice

The mRNA expression of P-selectin was significantly reduced by $17 \%(P=0.004)$ in the group supplemented with DDB (Fig. 2(A)) with respect to the control group. Beer supplementation had the greatest effect on the mRNA expression of VCAM-1 (20\%,P=0.012 and $32 \%$, $P=0.001$, of reduction for the DLB- and DDB-treated mice, respectively) (Fig. 2(B)). The mRNA expression of ICAM-1 was reduced in the two treated groups by about $14 \%$ (Fig. $2(\mathrm{C})$ ), but a significant difference $(P=0.014)$ was only detected for the DLB-treated mice.

\section{Dealcoholised beer-rich diets decreased the protein} expression of the endothelial adhesion molecules and $N F-\kappa B$ in the aortic root of apoE - /- mice

P-selectin, VCAM-1 and ICAM-1 were expressed in the aortic root of 24-week-old control apoE $-/-$ mice. We observed a reduction in P-selectin in the DDB-treated group (37\%, $P=0 \cdot 012)$. VCAM-1 was decreased by $48 \%$ $(P=0.001)$ and $54 \%(P<0.001)$ in the DLB- and DDBtreated groups, respectively, and ICAM-1 was reduced by

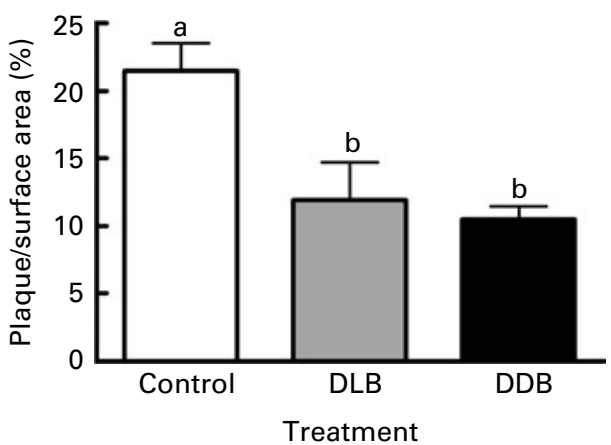

Fig. 1. Dietary supplementation with dealcoholised lager beer (DLB) and dealcoholised dark beer (DDB) for 20 weeks reduces the atheroma plaques in longitudinal sections of the thoracic aorta from apoE - /- mice. Percentage of atherosclerotic lesions relative to the total aortic area. Values are means, with standard errors represented by vertical bars $(n 8){ }^{\mathrm{a}, \mathrm{b}}$ Mean values with unlike letters were significantly different $(P<0.05)$.
$25 \%(P=0.028)$ and $30 \%(P=0.018)$ in the DLB- and DDB-treated groups, respectively (Fig. 2(D) $-(\mathrm{F})$ ).

NF-кB expression in apoE $-/-$ mice supplemented with DLB and DDB was reduced by 30 and $46 \%$, respectively (Fig. 3), but the reduction was only significant $(P=0.042)$ for the DDB-treated mice.

\section{Discussion}

Alcohol reduces the development of $\mathrm{CHD}^{(27)}$ regardless of the type of drink ${ }^{(28)}$. However, evidence also exists that components other than alcohol, such as polyphenols, might be involved in the protection afforded by beer ${ }^{(14)}$. Most of the polyphenols in beer come from the barley and hops. Polyphenols have antioxidant activity ${ }^{(11)}$, and we show here that the dealcoholisation of beers does not affect their total phenolic content or reducing power, and that $\mathrm{DB}$ and $\mathrm{DDB}$ have a significantly greater reducing power than LB and DLB. Moreover, we demonstrate here that the phenolic compounds from beer are absorbed and metabolised. Significant amounts of 4-hydroxyhippuric and 3,4-dihydroxyphenylacetic acids were present in the plasma from mice fed with dealcoholised beers for 20 weeks. These metabolites have been reported as microbial metabolites after consumption of several polyphenols from $\operatorname{cocoa}^{(24,26)}$ or quercetin ${ }^{(25)}$. Furthermore, both compounds inhibit the secretion of TNF- $\alpha$ in lipopolysaccharidestimulated peripheral blood mononuclear cells in vitro ${ }^{(29)}$. For all these reasons, we aimed to study the preventive effect of beer polyphenols on the development of atherosclerotic lesions and the possible underlying mechanisms.

The administration of alcohol-free beers did not change the plasma levels of TAG and total cholesterol in apoE - /mice. A controversy exists regarding the efficacy of beer polyphenols in reducing circulating lipids ${ }^{(14,30-33)}$, although most reliable data have been obtained from fasting animals. It is likely that many factors such as the amount of beer consumed, the age of initiation and the duration of the treatment, the presence or absence of alcohol or cholesterol in the diet and the species used would affect the results. In the present study, we used apoE $-/-$ mice, which have defects in TAG and VLDL clearance ${ }^{(2)}$. We found that the aortic lesions were reduced in both groups of dealcoholised beer-treated mice, even without a reduction in plasma cholesterol and TAG concentrations.

The surface area occupied by the atheroma plaques is high in the aortic arch of apoE $-/-$ mice, probably due to the turbulent flux generated by haemodynamic forces in the vascular endothelium ${ }^{(34)}$. Furthermore, Emeson et al. ${ }^{(35)}$ postulated that the atheroma plaque deposition follows a caudal direction towards the abdominal aorta and secondary arteries. Controversial results also exist regarding the modulation of atherosclerotic lesions in alcohol-free beer-fed animals ${ }^{(14,36)}$. In this sense, the present results can be compared to those of Vinson et $a l^{(14)}$, who administered diluted LB and DB to hamsters. It is 


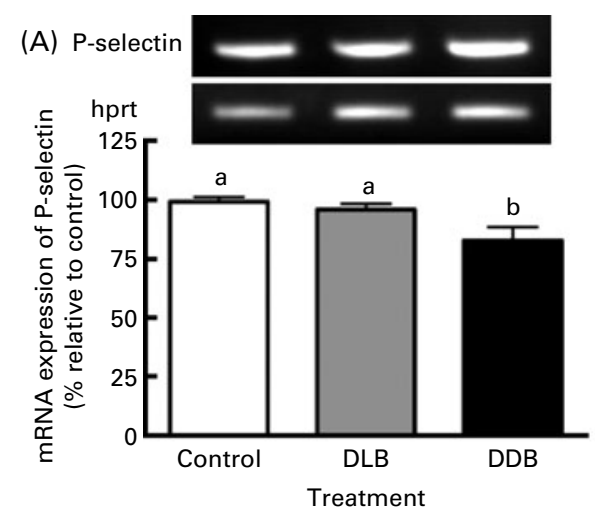

(D)

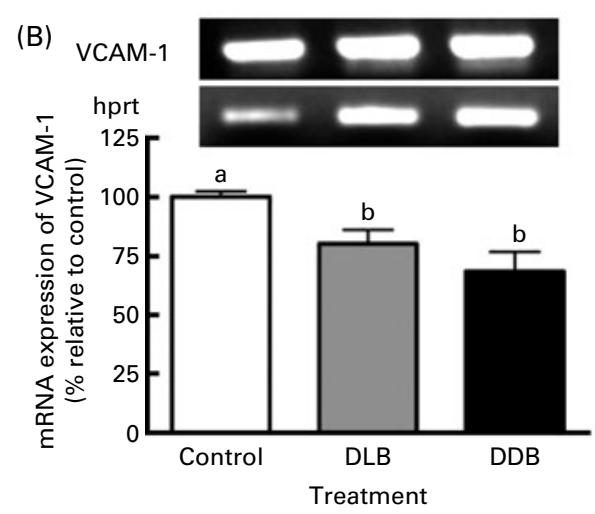

$(\mathrm{E})$

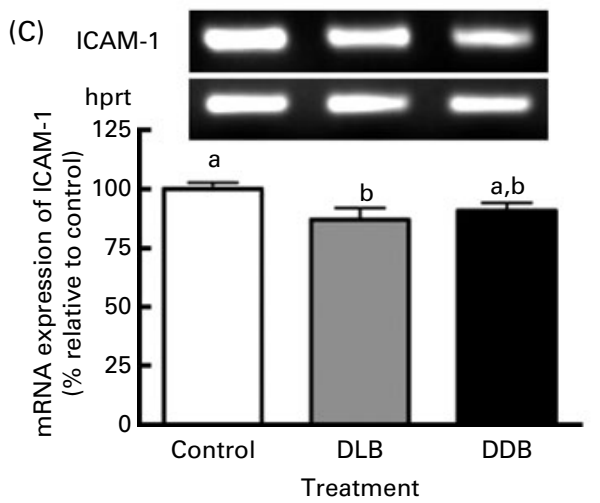

(F)
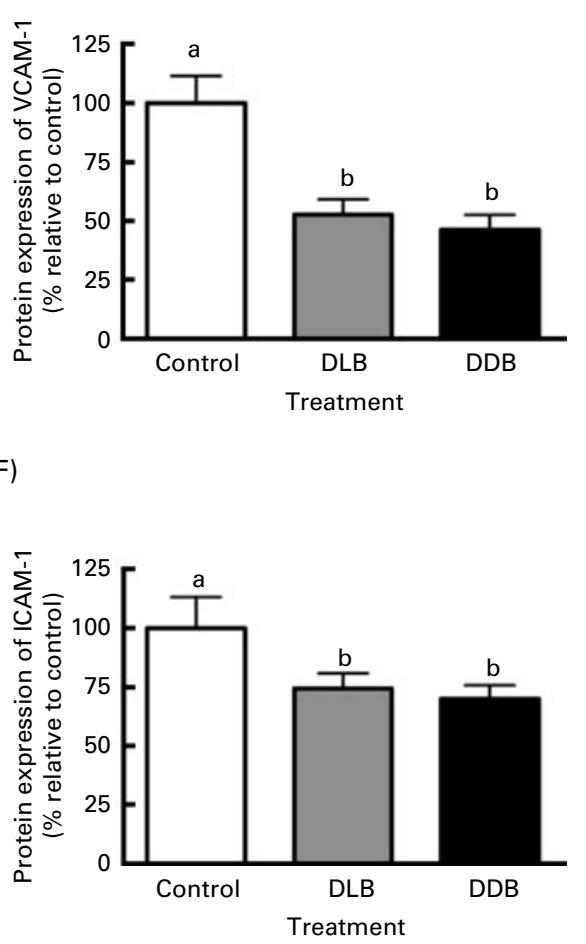

Fig. 2. Dietary supplementation with dealcoholised lager beer (DLB) and dealcoholised dark beer (DDB) for 20 weeks reduces the mRNA and protein expression of adhesion molecules in the total aorta and the aortic root, respectively, from apoE $-/-$ mice. Percentage of the mRNA or protein expression relative to the control group. (A) mRNA expression of P-selectin; (B) mRNA expression of vascular cell adhesion molecule-1 (VCAM-1); (C) mRNA expression of intercellular adhesion molecule-1 (ICAM-1); (D) protein expression of P-selectin; (E) protein expression of VCAM-1; (F) protein expression of ICAM-1. Values are means, with standard errors represented by vertical bars $(n 6)$. ${ }^{\mathrm{a}, \mathrm{b}}$ Mean values with unlike letters were significantly different $(P<0 \cdot 05)$. hprt, Hypoxanthine-guanine phosphoribosyl transferase.

evident that the protection afforded by beers in the present paper is due to their non-alcoholic compounds. The present results reinforce the proposal by Vinson et al. ${ }^{(14)}$ that beer is equally as effective as red wine against atherosclerosis, despite the much greater content of polyphenols in wine. One reason for this could be the larger amount of beer consumed compared with wine in the US population $^{(15)}$ and in Europe ${ }^{(16)}$. Nevertheless, the mechanisms underlying the beneficial effect against atherosclerosis are unknown.

Atherosclerosis is associated with an inflammatory process, with accumulation of leucocytes in the subendothelial space and the involvement of the endothelial adhesion molecules in this step. There are studies based on the modulation of the expression of adhesion molecules and other inflammatory markers by phenolic compounds from alcoholic drinks in healthy subjects ${ }^{(32,33,37,38)}$ or in inflammatory processes such as coronary arterial disease or atherosclerosis ${ }^{(39,40)}$. To the best of our knowledge, there are no reports focusing on the regulation of the inflammatory molecules by dealcoholised beers in atherosclerosis. Alcohol has been considered as responsible for the reduction of proinflammatory mediators ${ }^{(15,38)}$. However, polyphenols from alcoholic drinks decrease the 


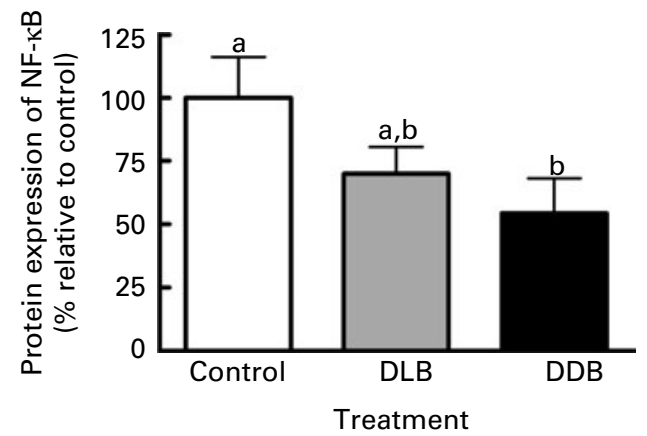

Fig. 3. Dietary supplementation with dealcoholised lager beer (DLB) and dealcoholised dark beer (DDB) for 20 weeks reduces the NF-кB expression in the aortic root from apoE $-1-$ mice. Percentage of protein expression relative to the control group. Values are means, with standard errors represented by vertical bars $(n 6) .{ }^{a, b}$ Mean values with unlike letters were significantly different $(P<0.05)$.

leucocyte interaction with the endothelium ${ }^{(40)}$ being also a clue for the protection in inflammation. A previous study by our group in which dealcoholised red wine was administered to healthy rats for 2 months showed reduced infiltration of polymorphonuclear leucocytes in an induced inflammatory process ${ }^{(12)}$, probably due to the antichemotactic effect of $\mathrm{NO}^{(41)}$ enhanced by wine polyphenols. This prompted us to perform the present study after administering dealcoholised beers to apoE $-/-$ mice. The phenolic microbial metabolites in the plasma were similar in both groups treated with dealcoholised beers, indicating a similar bioavailability of phenols in beers, which is in accordance with the small differences in the reducing power of beers and the mRNA and protein expression of endothelial adhesion molecules.

The higher effect on the expression of VCAM-1 by dealcoholised beers can be related to the fact that it is an inducible molecule and its expression is restricted to lesions and lesion-predisposed areas, whereas ICAM-1 is a constitutive molecule that is expressed in all areas ${ }^{(42)}$. Moreover, P-selectin mediates the rolling of monocytes, and its decrease following the DDB-rich diet should be regarded as an additional factor in the reduction of VCAM-1. The decrease in the mRNA expression of P-selectin, VCAM-1 and ICAM-1 was corroborated by immunofluorescence. These findings suggest that dealcoholised beers attenuate the initiation of atherosclerosis by down-regulating the expression of endothelial adhesion molecules. Taken together, these results indicate that the protection against atherosclerosis afforded by the two types of beer is similar, which may be attributable to the fact that they have a similar phenolic content, and to the small difference in the reducing power in beers and to similar phenolic microbial metabolites in the plasma of mice treated with dealcoholised beers. Thus, the present study provides evidence for an in vivo anti-inflammatory mechanism that should be investigated in humans. However, since immoderate consumption has been implicated in processes such as cancer and heart disease, it would be unwise to consider beer as a healthy food without further qualification.

The regulation of the expression of endothelial adhesion molecules is complex and is controlled by numerous molecules implicated in inflammatory processes; among these, $\mathrm{NF}-\kappa \mathrm{B}$ plays an important role $\mathrm{e}^{(7,43)}$. We observed a decreased expression of NF- $\mathrm{KB}$ in mice fed the dealcoholised beer-rich diets, which may explain the reduction in the endothelial adhesion molecule expression. No other study have reported the implication of $\mathrm{NF}-\kappa \mathrm{B}$ in the beneficial signalling pathways of beer polyphenols. Nevertheless, other studies have supported the attenuation of NF- $\kappa$ B expression by cis-resveratrol, a polyphenol present in beer and other drinks such as wine, in previously activated peritoneal macrophages ${ }^{(44)}$ or in the blood mononuclear cells of humans who had drunk red wine ${ }^{(45)}$. The procyanidins, another group of polyphenols, also inhibited the activation of this transcription factor in RAW 264.7 macrophages activated by lipopolysaccharide ${ }^{(46)}$.

In summary, the present study indicates, for the first time, a reduction in the expression of the endothelial adhesion molecules caused by DLB and DDB. This reduction is supported by a slower progression of atheroma plaques in apoE $-/-$ mice that spontaneously develop atherosclerosis when fed with dealcoholised beers, in the absence of a reduction in the high plasma levels of TAG and total cholesterol. Thus, we conclude that the protection afforded by DLB and DDB may be due to a decreased expression of NF- $\mathrm{\kappa B}$.

\section{Acknowledgements}

The authors thank the Serveis Científico-Tècnics from the Universitat de Barcelona for technical management and the Language Service at the Universitat de Barcelona for English language revision. The present study was financially supported by a grant from the Instituto de Cerveza y Salud, the Ministerio de Ciencia e Innovación (FIS project PI 05/2629; AGL2006-14228-C03-02/ALI) and the Instituto de Salud Carlos III (Alimentación saludable en la prevención primaria de enfermedades crónicas: Red PREDIMED, RD06/0045/0012). M. U.-S. thanks the Sara Borrell postdoctoral programme (CD09/00134) from the Ministry of Science and Innovation. N. M., M. U.-S., M. A. M.-G., C. A.-L. and M. T. M. designed the research and wrote the manuscript; N. M. and M. U.-S. conducted the research and analysed the data; C. A.-L. and M. T. M. provided essential materials and had primary responsibility for the final content. All the authors read and approved the final manuscript. None of the authors had a personal or financial conflict of interests.

\section{References}

1. Ross R (1999) Atherosclerosis - an inflammatory disease. $N$ Engl J Med 340, 115-126. 
2. Mahley RW \& Rall SC Jr (2000) Apolipoprotein E: far more than a lipid transport protein. Annu Rev Genomics Hum Genet 1, 507-537.

3. Osada J, Joven J \& Maeda N (2000) The value of apolipoprotein $\mathrm{E}$ knockout mice for studying the effects of dietary fat and cholesterol on atherogenesis. Curr Opin Lipidol 11, 25-29.

4. Lasky LA (1992) Selectins: interpreters of cell-specific carbohydrate information during inflammation. Science $\mathbf{2 5 8}$, 964-965.

5. Adams DH \& Shaw S (1994) Leucocyte-endothelial interactions and regulation of leucocyte migration. Lancet $\mathbf{3 4 3}$, 831-836.

6. Nakashima Y, Raines EW, Plump AS, et al. (1998) Upregulation of VCAM-1 and ICAM-1 at atherosclerosis-prone sites on the endothelium in the ApoE-deficient mouse. Arterioscler Thromb Vasc Biol 18, 842-851.

7. Barnes PJ \& Karin M (1997) Nuclear factor-kappaB: a pivotal transcription factor in chronic inflammatory diseases. $N$ Engl J Med 336, 1066-1071.

8. Hertog MG, Kromhout D, Aravanis C, et al. (1995) Flavonoid intake and long-term risk of coronary heart disease and cancer in the seven countries study. Arch Intern Med 155, 381-386.

9. Renaud S \& de Lorgeril M (1992) Wine, alcohol, platelets, and the French paradox for coronary heart disease. Lancet 339, 1523-1526.

10. Brenner H, Rothenbacher D, Bode G, et al. (2001) Coronary heart disease risk reduction in a predominantly beerdrinking population. Epidemiology 12, 390-395.

11. Rice-Evans CA, Miller NJ \& Paganga G (1996) Structureantioxidant activity relationships of flavonoids and phenolic acids. Free Radic Biol Med 20, 933-956.

12. Lopez D, Pavelkova M, Gallova L, et al. (2007) Dealcoholized red and white wines decrease oxidative stress associated with inflammation in rats. BrJ Nutr 98, 611-619.

13. Whitehead TP, Robinson D, Allaway S, et al. (1995) Effect of red wine ingestion on the antioxidant capacity of serum. Clin Chem 41, 32-35.

14. Vinson JA, Mandarano M, Hirst M, et al. (2003) Phenol antioxidant quantity and quality in foods: beers and the effect of two types of beer on an animal model of atherosclerosis. J Agric Food Chem 51, 5528-5533.

15. Klatsky AL, Armstrong MA \& Friedman GD (1997) Red wine, white wine, liquor, beer, and risk for coronary artery disease hospitalization. Am J Cardiol 80, 416-420.

16. Pyorala E (1990) Trends in alcohol consumption in Spain, Portugal, France and Italy from the 1950s until the 1980s. Br J Addict 85, 469-477.

17. Sierksma A, van der Gaag MS, Kluft C, et al. (2002) Moderate alcohol consumption reduces plasma C-reactive protein and fibrinogen levels; a randomized, diet-controlled intervention study. Eur J Clin Nutr 56, 1130-1136.

18. Pinkel D (1958) The use of body surface area as a criterion of drug dosage in cancer chemotherapy. Cancer Res 18, 853-856.

19. Benito S, Buxaderas S \& Mitjavila MT (2004) Flavonoid metabolites and susceptibility of rat lipoproteins to oxidation. Am J Physiol Heart Circ Physiol 287, H2819-H2824.

20. Singleton VL \& Rossi JA (1965) Colorimetric of total phenolics with phosphomolybdic-phosphotungstic acid reagents. Am J Enol Viticult 16, 144-158.

21. Oyaizu M (1986) Studies on products of browning reaction: antioxidative activities of products of browning reaction prepared from glucosamine. Jpn J Nutr 44, 307-315.

22. Gerhauser C (2005) Beer constituents as potential cancer chemopreventive agents. Eur J Cancer 41, 1941-1954.
23. Urpi-Sarda M, Monagas M, Khan N, et al. (2009) Epicatechin, procyanidins, and phenolic microbial metabolites after cocoa intake in humans and rats. Anal Bioanal Chem 394, 1545-1556.

24. Rios LY, Gonthier MP, Rémésy C, et al. (2003) Chocolate intake increases urinary excretion of polyphenol-derived phenolic acids in healthy human subjects. Am J Clin Nutr 77, 912-918.

25. Selma MV, Espín JC \& Tomás-Barberán FA (2009) Interaction between phenolics and gut microbiota: role in human health. J Agric Food Chem 57, 6485-6501.

26. Urpi-Sarda M, Llorach R, Khan N, et al. (2010) Effect of milk on the urinary excretion of microbial phenolic acids after cocoa powder consumption in humans. J Agric Food Chem 58, 4706-4711.

27. Hashimoto Y, Futamura A, Nakarai H, et al. (2001) Effects of the frequency of alcohol intake on risk factors for coronary heart disease. Eur J Epidemiol 17, 307-312.

28. Mukamal KJ, Conigrave KM, Mittleman MA, et al. (2003) Roles of drinking pattern and type of alcohol consumed in coronary heart disease in men. N Engl J Med 348, 109-118.

29. Monagas M, Khan N, Andrés-Lacueva C, et al. (2009) Dihydroxylated phenolic acids derived from microbial metabolism reduce lipopolysaccharide-stimulated cytokine secretion by human peripheral blood mononuclear cells. Br J Nutr 102, 201-206.

30. Degrace P, Moindrot B, Mohamed I, et al. (2006) Moderate consumption of beer reduces liver triglycerides and aortic cholesterol deposit in LDLr - /- apoB100/100 mice. Atherosclerosis 189, 328-335.

31. Gasowski B, Leontowicz M, Leontowicz H, et al. (2004) The influence of beer with different antioxidant potential on plasma lipids, plasma antioxidant capacity, and bile excretion of rats fed cholesterol-containing and cholesterolfree diets. J Nutr Biochem 15, 527-533.

32. Martinez Alvarez JR, Belles VV, Lopez-Jaen AB, et al. (2009) Effects of alcohol-free beer on lipid profile and parameters of oxidative stress and inflammation in elderly women. Nutrition 25, 182-187.

33. Tousoulis D, Ntarladimas I, Antoniades C, et al. (2008) Acute effects of different alcoholic beverages on vascular endothelium, inflammatory markers and thrombosis fibrinolysis system. Clin Nutr 27, 594-600.

34. Frangos SG, Gahtan V \& Sumpio B (1999) Localization of atherosclerosis: role of hemodynamics. Arch Surg 134, 1142-1149.

35. Emeson EE, Manaves V, Singer T, et al. (1995) Chronic alcohol feeding inhibits atherogenesis in C57BL/6 hyperlipidemic mice. Am J Pathol 147, 1749-1758.

36. Escola-Gil JC, Calpe-Berdiel L, Ribas V, et al. (2004) Moderate beer consumption does not change early or mature atherosclerosis in mice. Nutr J 3, 1-7.

37. Vazquez-Agell M, Sacanella E, Tobias E, et al. (2007) Inflammatory markers of atherosclerosis are decreased after moderate consumption of cava (sparkling wine) in men with low cardiovascular risk. J Nutr 137, 2279-2284.

38. Imhof A, Blagieva R, Marx N, et al. (2008) Drinking modulates monocyte migration in healthy subjects: a randomised intervention study of water, ethanol, red wine and beer with or without alcohol. Diab Vasc Dis Res 5, 48-53.

39. Williams MJ, Sutherland WH, Whelan AP, et al. (2004) Acute effect of drinking red and white wines on circulating levels of inflammation-sensitive molecules in men with coronary artery disease. Metabolism 53, 318-323.

40. Appeldoorn CC, Bonnefoy A, Lutters BC, et al. (2005) Gallic acid antagonizes P-selectin-mediated platelet-leukocyte interactions: implications for the French paradox. Circulation 111, 106-112. 
41. Hickey MJ (2001) Role of inducible nitric oxide synthase in the regulation of leucocyte recruitment. Clin Sci (Lond) 100, $1-12$

42. Iiyama K, Hajra L, Iiyama M, et al. (1999) Patterns of vascular cell adhesion molecule-1 and intercellular adhesion molecule-1 expression in rabbit and mouse atherosclerotic lesions and at sites predisposed to lesion formation. Circ Res 85, 199-207.

43. Boyle EM Jr, Kovacich JC, Canty TG Jr, et al. (1998) Inhibition of nuclear factor-kappa $\mathrm{B}$ nuclear localization reduces human E-selectin expression and the systemic inflammatory response. Circulation 98, II282-II288.
44. Leiro J, Arranz JA, Fraiz N, et al. (2005) Effect of cis-resveratrol on genes involved in nuclear factor kappa B signaling. Int Immunopharmacol 5, 393-406.

45. Blanco-Colio LM, Valderrama M, Alvarez-Sala LA, et al. (2000) Red wine intake prevents nuclear factor-kappaB activation in peripheral blood mononuclear cells of healthy volunteers during postprandial lipemia. Circulation 102, $1020-1026$.

46. Terra X, Valls J, Vitrac X, et al. (2007) Grape-seed procyanidins act as antiinflammatory agents in endotoxin-stimulated RAW 264.7 macrophages by inhibiting NFкB signaling pathway. J Agric Food Chem 55, 4357-4365. 